Sangpradid, S., Uttaruk, Y.,Rotjanakusol, T., Laosuwan T. (2021): Forecasting time series change of the average enhanced vegetation index to monitoring drought condition by using terra/modis data. Agriculture and Forestry, 67 (4): 115-129. doi:10.17707/AgricultForest.67.4.10

DOI: 10.17707/AgricultForest.67.4.10

\author{
Satith SANGPRADID ${ }^{I}$, Yannawut UTTARUK ${ }^{2}$, \\ Tanutdech ROTJANAKUSOL ${ }^{3}$, Teerawong LAOSUWAN ${ }^{3 *}$

\section{FORECASTING TIME SERIES CHANGE OF THE AVERAGE ENHANCED VEGETATION INDEX TO MONITORING DROUGHT CONDITION BY USING TERRA/MODIS DATA}

\title{
SUMMARY
}

Drought condition is a natural disaster that has caused economic and social damages considerably including a shortage of consuming water, and has been a hindrance to the agricultural production and industrial development. Currently, the drought condition tends to be more severe in Yasothon Province of Thailand, thus affecting plantation in the area. The purpose of this study was to monitor the drought condition of Yasothon Province, which is located in the Northeastern region of Thailand, by using Enhanced Vegetation Index (EVI) data during 2010 - 2019 obtained from Terra/Modis Satellite, and by studying the change in time series from the average EVI during 2010 - 2019, for the forecast in 2020 - 2022 by using moving averages method and exponential smoothing method in order to compare the differences between the original data of average EVI and the data of average EVI adjusted by smoothing algorithm using RMMEH method. Statistics used in examining the forecasting accuracy were MAD and MAPE. It was found from the study that MAD and MAPE of the forecast of the original average EVI and the average EVI adjusted by using RMMEH method were slightly different in that the average EVI adjusted by using RMMEH method and forecasted by moving averages method was best accurate. In addition, according to the time series change forecast of EVI, it was found that the original average EVI and the EVI which was smoothed by RMMEH method of the forecasting year during 2020 - 2022 by using moving average method and exponential smoothing method were very low in each year, indicating that the drought would occur in the future.

Keywords: Enhanced Vegetation Index (EVI), Remote Sensing, Drought, RMMEH method

\footnotetext{
${ }^{1}$ Satith Sangpradid, Department of Informatics, Faculty of Geoinformatics, Mahasarakham University, Khamrieng, Katarawichai, Maha Sarakham, 44150, THAILAND.

2 Yannawut Uttaruk, Department of Biology, Faculty of Science, Mahasarakham University, Khamrieng, Katarawichai, Maha Sarakham, 44150, THAILAND

${ }^{3}$ Tanutdech Rotjanakusol, Teerawong Laosuwan* (corresponding author: teerawong@msu.ac.th), Department of Physics, Faculty of Science, Mahasarakham University, Khamrieng, Katarawichai, Maha Sarakham, 44150, THAILAND

Notes: The author declares that he has no conflicts of interest. Authorship Form signed online. 


\section{INTRODUCTION}

Drought condition is a natural disaster found in many areas and has caused huge damage and had greatly hindered the national development of Thailand. The areas affected by drought condition often face a shortage of consuming water and water supply used for farming which relies heavily on rainwater (Laosuwan, et al., 2016). When there is insufficient amount of water, the agricultural yields decrease, thus causing a lack of agricultural products and processed products for domestic consumption and for exporting. The drought condition in the Northeastern region of Thailand has long been taking place and has been considered as the serious problem mainly due to a shortage of rainfall, and other factors including the soil water retention, underground water source, and the use of land.

The drought is caused by a lack of rainfall during rainy season and the irregularity of raining time between June to July (Rotjanakusol \& Laosuwan, 2018). In addition, according to the analysis into rainfall pattern in terms of space and time, it was found that there would be no rain after the latter half of September as well since the area cannot be accessed by the Southwestern monsoon; and if in any year there is no tropical cyclone moving through such area, the drought would turn out to be more serious. Main consequences from the drought include a lack of consuming water, water supply used in various activities especially in farming. Farming is the main career of people living in Northeastern region; therefore, a lack of water does cause substantial impact on the cultivation thus decreasing the crop yields leading to the economic, social, and environmental problems, as well as health issue such as the epidemic disease that occurs during the dry season (Rotjanakusol \& Laosuwan, 2019a).

The severity of drought condition depends on many factors including physical factor, ecological factor, and human activities factor. Therefore, the rainfall is regarded as the significant factor to be used when finding the relationship pattern with the spectral index and to study the duration of rainwater that affects plantation (Mongkolsawat et al., 2001; Dutta, et al., 2015; Gomasathit et al., 2015). The relationship between the rainfall and the spectral index is a key variable used to determine the drying area (Thavorntam et al., 2015; Lines et al., 2017; Nistor et al., 2018). The phenological change of plants in dry area could appear as the reflection of electromagnetic wave differently that could be seen by satellite data (Tucker, 1979; Peters et al., 2012; Seekaw et al., 2014; Uttaruk \& Laosuwan, 2018). However, in studying drought condition, data have to be adjusted for the suitability of use and for the increased efficiency in showing more clearly whatever being studied. The data adjustment of this sort is called Index (Vrieling et al., 2014; Klisch \& Atzberger, 2016; Uttaruk \& Laosuwan, 2017; Rotjanakusol \& Laosuwan, 2019b). The spectral index which is associated with the physical characteristics of plants and amount of water in plants and in soil can identify the drought condition (Kogan, 2001; Fan et al., 2015; Li et al., 2015; Uttaruk \& Laosuwan, 2020a) for example, in the calculation for Enhanced Vegetation Index (EVI), the results of such can identify the growth and fertility of 
plants in each climatic condition duration (Season) very well (Holben \& Justice, 1981; Matsushita et al., 2007). Currently, the study of natural resources is performed by using remote sensing technology used with the application of satellite data in the study. The aim to apply this technology is to reduce time spent in physical exploration in the actual area. Nowadays, a lot of satellite data, both low and high spatial resolution, are used (Uttaruk \& Laosuwan, 2020b; Prohmdirek et al., 2020; Auntarin et al., 2021; Piamdee \& Laosuwan, 2021). The study of time series forecast is to study the changing pattern of data that have occurred from the past until the present time $(\mathrm{Gu}, 2007)$ the extent of data change depends on the pattern of data to be studied (Furtuna et al., 2015), which is the same as natural resources data. Therefore, in studying the time series forecast of EVI, it is to make quantitative comparison; the time series forecast is a quantitative forecast where there are both linear and non-linear methods each of which has its own limitation. The study of change in EVI data to be used in time series forecast is performed using linear method (Li et al., 2014).

Consequently, in this study, EVI was used to study the drought condition together with the time series forecast, by studying the change from the average EVI obtained from Terra/Modis Satellite during 2010 - 2019, in forecasting for 2020 - 2012. In this forecast, the average EVI data adjusted by smoothing algorithm method was used by using RMMEH method (Jin et al., 2013) from Terra/Modis satellite data to be used in the forecast, by applying Moving Averages Method and Exponential Smoothing Methods

\section{Moving Averages Method}

\section{MATERIAL AND METHODS}

The moving average is a smoothing tool for the convenience in monitoring the trend. Basically, the average would help spread the abnormalities out of the moving averages data used to predict the future. The moving averages method pattern is as shown in Equation 1.

$$
Y_{t+1}=\frac{Y_{t}+Y_{t-1}+Y_{t-2}+\ldots+Y_{t-N+1}}{N}
$$

Where;

$$
\begin{aligned}
& \mathrm{Y}_{\mathrm{t}+1}=\text { prediction value over time } \mathrm{t}+1 \\
& \mathrm{Y}_{\mathrm{t}}=\text { data value in the current period }(\mathrm{t}) \\
& \mathrm{N}=\text { number of data used to mean }
\end{aligned}
$$

\section{Exponential Moving Average}

This is the method for data forecast with the same principle as the weighed moving average which is quite complicated; the error occurring from the forecast is used to adjust the next average for more accuracy, however, it is easily applied. The pattern of exponential moving average is as shown in Equation 2. 


$$
\hat{\mathrm{Y}}_{\mathrm{t}+1}=\mathrm{aY}+(1-\mathrm{a}) \hat{\mathrm{Y}}_{\mathrm{t}}
$$

Where;

$\hat{\mathrm{Y}}_{\mathrm{t}+1}=$ the new smoothing or the value for the next forecast

$\mathrm{a}=$ the constant smoothing modifier $(0<\mathrm{a}<1)$

$\mathrm{Y}_{\mathrm{t}}=$ the new data value or the actual value of the time series $\mathrm{t}$

$\hat{Y}_{t}=$ the old smoothing or forecast period $t$

\section{Enhanced Vegetation Index (EVI)}

This is the method for solve the problem of the response of light reflection from soil and climate. It is reported that EVI is more associated with the spatial index of leaves surface than normalized differences vegetation index. And according to the past study, it was found that EVI is more sensitive to parameters in area where there is more density of leaves than Normalized Difference Vegetation Index (NDVI). The pattern of EVI is as shown in Equation 3.

$$
\mathrm{EVI}=\mathrm{G} \times \frac{\mathrm{NIR}-\mathrm{RED}}{\mathrm{NIR}+\left(\mathrm{C}_{1} \times \mathrm{RED}-\mathrm{C}_{2} \times \mathrm{BLUE}\right)+\mathrm{L}}
$$

Where;

EVI $=$ Enhanced Vegetation Index

$\mathrm{G}=$ Gain Factor

NIR $=$ percentage of reflection in the near infrared spectrum

RED $=$ percentage reflection in the visible red spectrum

$\mathrm{BLUE}=$ percentage reflection in the visible blue spectrum

$\mathrm{C}_{1} \mathrm{C}_{2}=$ coefficient for dust particles in the atmosphere

$\mathrm{L}=$ correction factor for the soil

\section{Adjusting EVI data by smoothing algorithm}

This is the technique in adjusting data by smoothing algorithm, which is called RMMEH to be used in adjusting EVI from Terra/ Modis Satellite; the procedures are as follows: (1) Finding $M_{t}$ is to find the average EVI of the selected year. The pattern in finding $M_{t}$ is as shown in Equation 4; (2) finding $R_{t}$ or the median from 5 periods of time which are in close proximity. The pattern in finding $M_{t}$ is shown as in Equation 5, and (3) finding $E_{\text {RMM }} t$ is to find maximum value from EVI, $\mathrm{M}_{\mathrm{t}}$, and $\mathrm{R}_{\mathrm{t}}$ of EVI of the studied year. The pattern in finding $\mathrm{EVI}_{\mathrm{RMM}_{\mathrm{t}} \mathrm{i}}$ is as shown in Equation 6.

$$
\mathrm{M}_{\mathrm{t}}=\frac{\left(\mathrm{EVI}_{\mathrm{t}-1}+\mathrm{EVI}_{\mathrm{t}+1}\right)}{2}
$$

Where; 
$\mathrm{M}_{\mathrm{t}} \quad=\quad$ mean of the EVI over time $\mathrm{t}$

$\mathrm{EVI}_{\mathrm{t}-1}=$ previous year's EVI of the period $\mathrm{t}$

$\mathrm{EVI}_{\mathrm{t}+1}=$ next year's EVI of the period $\mathrm{t}$

$$
\mathrm{R}_{\mathrm{t}}=\mathrm{RM}_{5}\left(\mathrm{EVI}_{\mathrm{t}-2}, \mathrm{EVI}_{\mathrm{t}-1}, \mathrm{EVI}_{\mathrm{t}}, \mathrm{EVI}_{\mathrm{t}+1}, \mathrm{EVI}_{\mathrm{t}+2}\right)
$$

Where;

$\mathrm{R}_{\mathrm{t}}=$ median of all $5 \mathrm{EVI}$ values of time $\mathrm{t}$

$\mathrm{RM}_{5}=$ median of the EVI value of time $\mathrm{t}$

$\mathrm{EVI}_{\mathrm{t}-1}=$ previous year's EVI of the period $\mathrm{t}$

$\mathrm{EVI}_{\mathrm{t}-2}=\mathrm{EVI}$ of the previous 2 years of the period $\mathrm{t}$

$\mathrm{EVI}_{\mathrm{t}+1}=$ next year's EVI of the period $\mathrm{t}$

$\mathrm{EVI}_{\mathrm{t}+2}=\mathrm{EVI}$ of the next 2 years of the period $\mathrm{t}$

$$
\mathrm{EVI}_{\mathrm{RMM}_{-} \mathrm{t}}=\mathrm{MAX}\left(\mathrm{EVI}_{\mathrm{t}}, \mathrm{M}_{\mathrm{t}}, \mathrm{R}_{\mathrm{t}}\right)
$$

Where;

$\mathrm{EVI}_{\mathrm{RMM}_{-} \mathrm{t}}=\mathrm{EVI}$ of the period $\mathrm{t}$

$\mathrm{M}_{\mathrm{t}}=$ mean of the interval $\mathrm{t}$

$\mathrm{R}_{\mathrm{t}}=$ median of the period $\mathrm{t}$

\section{Checking for forecast accuracy}

This is the checking for forecast accuracy of moving averages method and exponential smoothing method was performed. In this study, the accuracy was measured in the following ways: (1) mean absolute deviation (MAD): it is to check for the mean absolute deviation of the forecast, which is very useful for the analysis where deviation in the same unit with the original time series data was to be examined. The pattern in finding MAD is shown as in Equation 7; and (2) mean absolute percentage error (MAPE): this can be calculated by taking the actual error in each period to be divided by actual data in such period and then averaging the actual error in percentage. The pattern in finding MAPE is shown as in Equation 8.

$$
\mathrm{MAD}=\frac{\Sigma \mid \text { actual values-Forecast } \mid}{\mathrm{n}}
$$

Where;

$$
\begin{array}{ll}
\text { actual values } & =\text { observation at a particular time } \\
\text { Forecast } & =\text { forecast value at a particular time } \\
\mathrm{n} & =\text { number of comparative data }
\end{array}
$$




$$
\text { MAPE }=\left[\frac{\Sigma \mid \text { Actual values-Forecast } \mid \div \text { Actual values }}{n}\right] \times 100
$$

Where;

$$
\begin{array}{ll}
\text { actual values } & =\text { observation at a particular time } \\
\text { Forecast } & =\text { forecast value at a particular time } \\
\mathrm{n} & =\text { number of comparative data }
\end{array}
$$

\section{The Study area}

The study area in this study is Yasothon Province, located at the Northeastern region of Thailand (Figure 1), at the latitude of $15-16^{\circ} \mathrm{N}$ and longitude of $104-105^{\circ} \mathrm{E}, 128$ meters above sea level, with the area of about $4,161.44 \mathrm{~km}^{2}$, or equal to $0.81 \%$ of total area of the country. Yasothon area is characterized by slope from the west side down to the east side; much of the soil is sandy and salty. At the upper part of the Province, much of it is high plain area alternated by undulating area, and some areas consist of forests and small mountains.

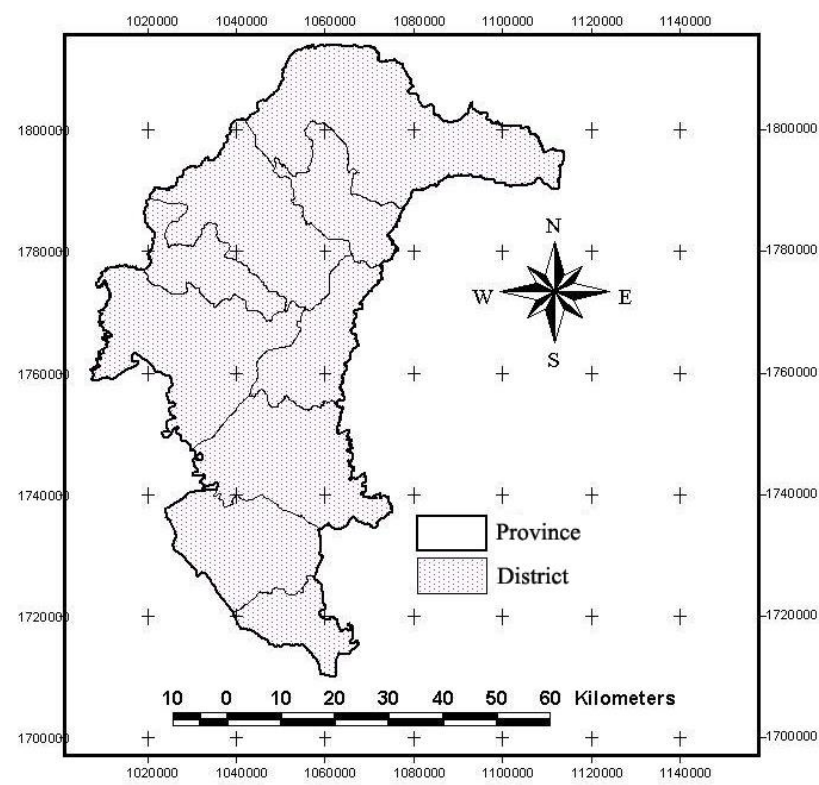

Figure 1. Yasothon Province

\section{Data from satellite}

Terra/ Modis Satellite is designed with the aim to follow and monitor natural resources data with swatch of about $2,330 \mathrm{~km}$, with spatial resolution of $250 \mathrm{~m}$ to $1000 \mathrm{~m}$, with 36 band recording system, and data from areas all over the world can be recorded within 2 days. In this study, MOD13Q1 product was used to cover the studied area during $2010-2019$. 


\section{Methodology}

For the benefit of brevity of the presentation of methodology used in this study, the conclusion was made by using research framework as shown in Figure 2 with the brief procedures as follows: (1) analyze EVI from Terra/ Modis Satellite data in the year of 2010 - 2019, and the average EVI could be analyzed and found by using Equation 3; (2) adjust the average EVI by using smoothing algorithm using RMMEH method from Equation 4, 5, and 6, respectively; (3) predict the land use in terms of time of EVI and EVI index where smoothing algorithm was applied already by using RMMEH method and by using moving averages method and exponential smoothing method; and (4) check for accuracy and compare the results of the study.

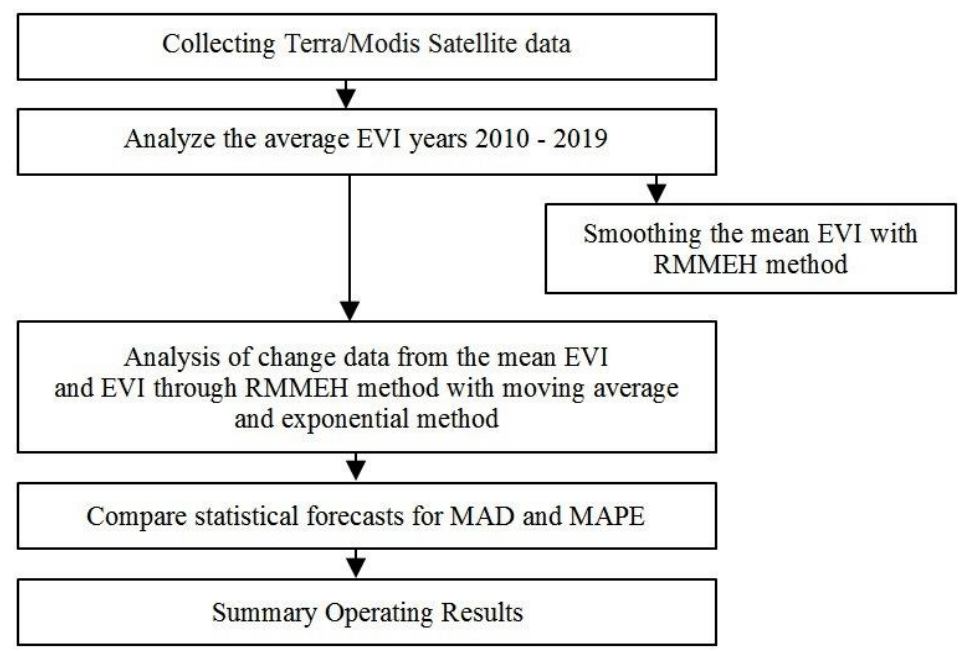

Figure 2. Research framework

\section{RESULTS AND DISCUSSION}

In time series change forecast of the average EVI to examine the drought condition from Terra/Modis Satellite data during 10 years $(2010$ - 2019) in Yasothon Province, the results of the study were as follows:

\section{Result from finding EVI}

According to the study during 10 years $(2010$ - 2019) (Figure 3 and Table 1), it was possible to identify the differences of quantity and fertility of plants in the area; EVI was -1 to 1 . Generally, green plants would have EVI of $0.2-0.8$. According to Table 1, it could be concluded that the maximum value, the minimum value, means, and standard deviation of EVI during $2010-2019$ in each period revealed different EVI between -1 to 1; such figure was consistent with the theory. The means could identify the condition of plants in the area or the drought condition in each period of time; the minimum means was 0.120 in 2011, and the maximum means was 0.139 in 2016. 

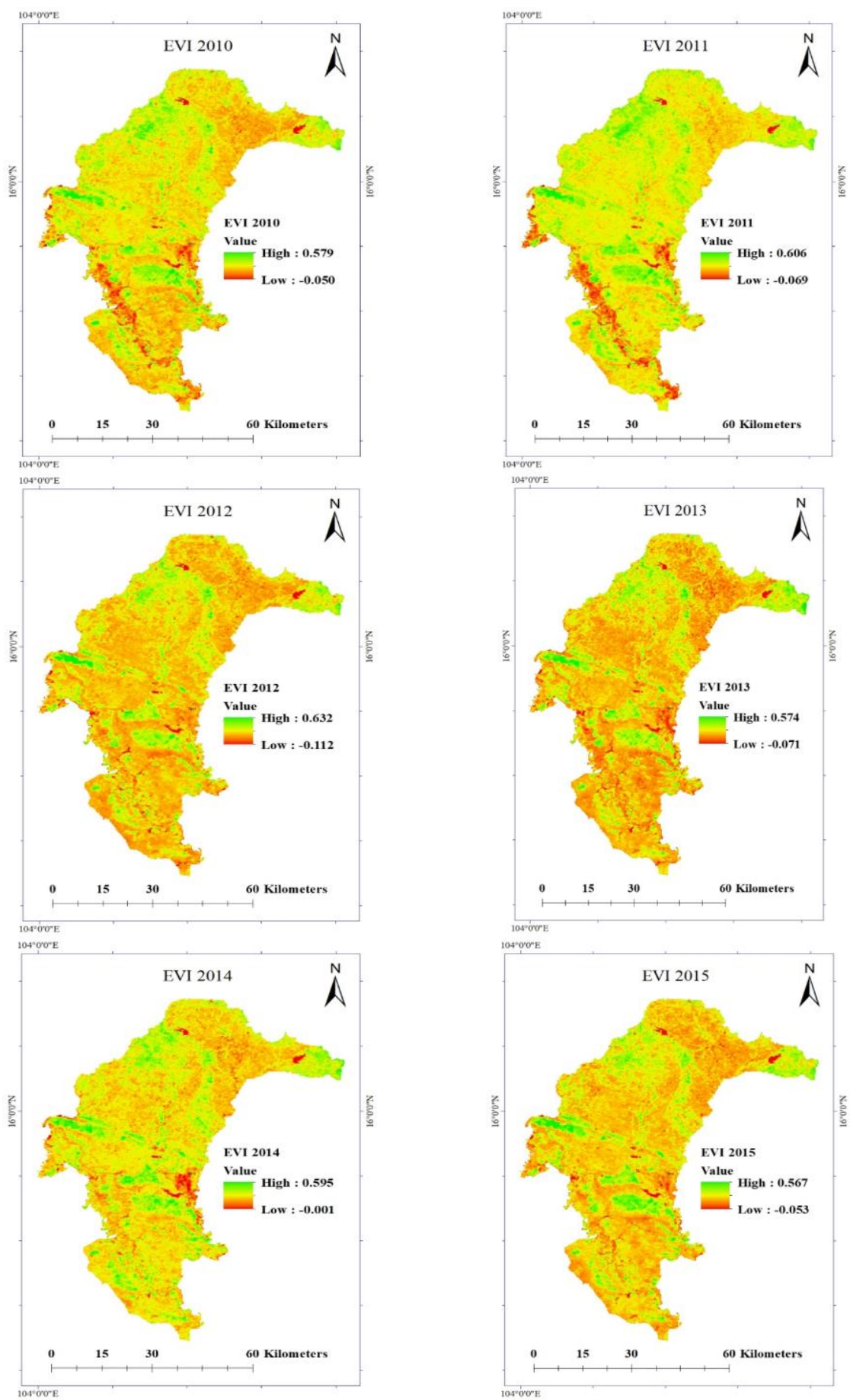

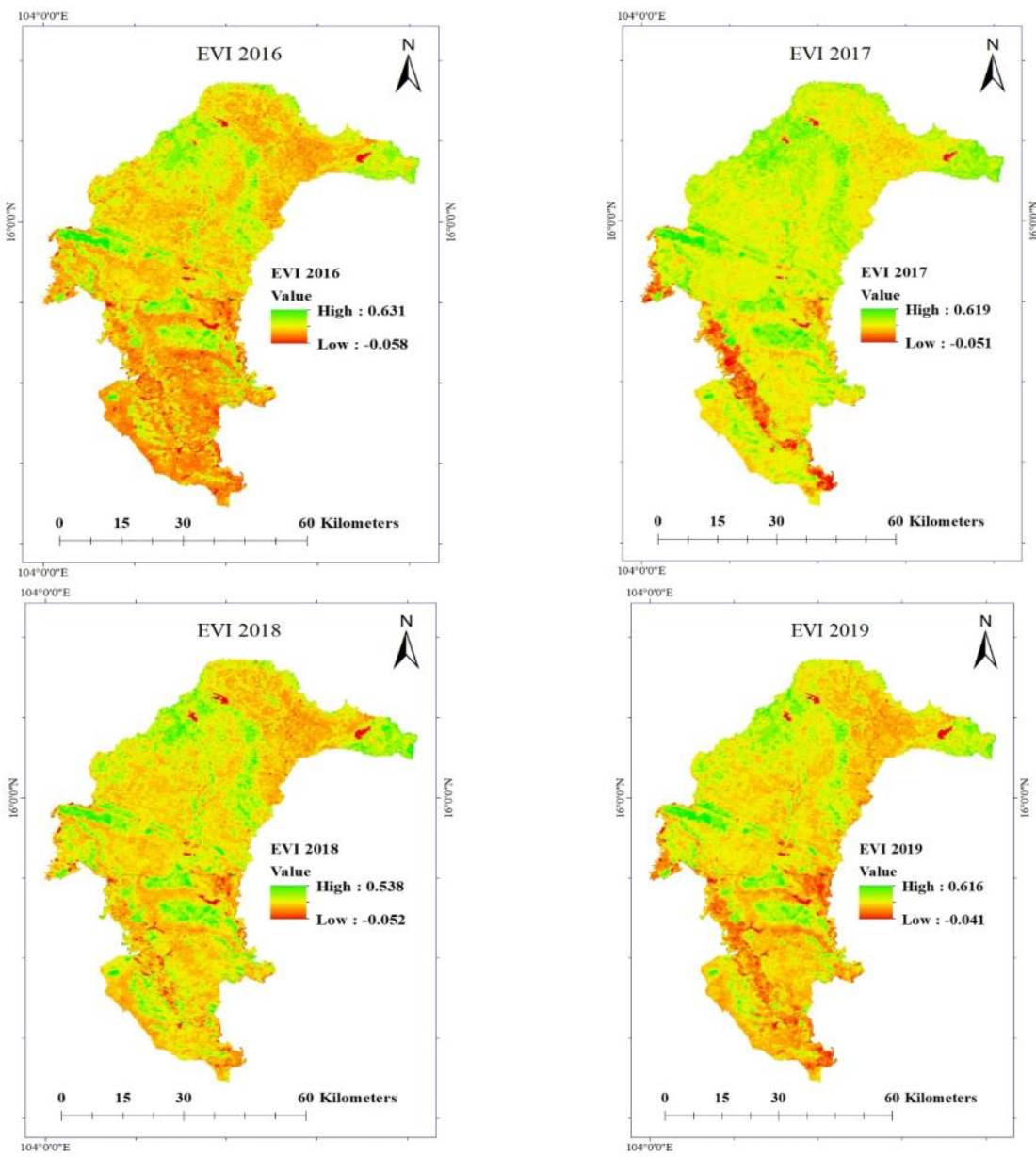

Figure 3. Spatial analysis of EVI during 10 years

Table 1. Minimum, Maximum, Mean, Standard Deviation of EVI

\begin{tabular}{ccccc}
\hline Year & Minimum & Minimum & Mean & $\begin{array}{c}\text { Standard } \\
\text { Deviation }\end{array}$ \\
\hline 2010 & -0.050 & 0.579 & 0.123 & 0.155 \\
2011 & -0.069 & 0.606 & 0.120 & 0.154 \\
2012 & -0.112 & 0.632 & 0.133 & 0.168 \\
2013 & -0.071 & 0.574 & 0.125 & 0.158 \\
2014 & -0.001 & 0.595 & 0.130 & 0.164 \\
2015 & -0.053 & 0.567 & 0.131 & 0.165 \\
2016 & -0.058 & 0.631 & 0.139 & 0.176 \\
2017 & -0.051 & 0.619 & 0.130 & 0.166 \\
2018 & -0.052 & 0.538 & 0.123 & 0.157 \\
2019 & -0.041 & 0.616 & 0.138 & 0.176 \\
\hline
\end{tabular}




\section{Result from time series change analysis}

For the results of the analysis into the average EVI from Terra/ Modis Satellite data with smoothing algorithm by using RMMEH method, EVI, $\mathrm{M}_{\mathrm{t}}, \mathrm{R}_{\mathrm{t}}$, and $\mathrm{EVI}_{\mathrm{RMM}_{\mathrm{t}}}$ of the average EVI during $2010-2019$ could be shown as in Table 2.

Table 2. the average EVI with smoothing algorithm using RMMEH method

\begin{tabular}{ccccc}
\hline Year & EVI & $\mathrm{M}_{\mathrm{t}}$ & $\mathrm{R}_{\mathrm{t}}$ & $\mathrm{EVI}_{\mathrm{RMM}_{-} \mathrm{t}}$ \\
\hline 2010 & 0.123 & 0.124 & 0.124 & 0.124 \\
2011 & 0.120 & 0.128 & 0.124 & 0.128 \\
2012 & 0.133 & 0.122 & 0.128 & 0.133 \\
2013 & 0.125 & 0.131 & 0.128 & 0.131 \\
2014 & 0.130 & 0.128 & 0.130 & 0.130 \\
2015 & 0.131 & 0.134 & 0.131 & 0.134 \\
2016 & 0.139 & 0.130 & 0.130 & 0.139 \\
2017 & 0.130 & 0.131 & 0.130 & 0.131 \\
2018 & 0.123 & 0.130 & 0.130 & 0.130 \\
2019 & 0.138 & 0.126 & 0.130 & 0.138 \\
\hline
\end{tabular}

\section{The result of time series forecast from the original average EVI that had} Smoothing Algorithm by RMMEH method

The results of time series forecast from the original average EVI that had Smoothing Algorithm by RMMEH method were shown in Table 3 and Table 4. It was found that the original average EVIs of the forecasted years which were in $2020-2022$ by using moving averages method were $0.130,0.130$, and 0.132 , respectively, and by using the exponential smoothing method, were $0.126,0.126$, and 0.126 , respectively.

Table 3. The time series forecast from the original average EVI

\begin{tabular}{cccc}
\hline Year & EVI & Moving Average & $\begin{array}{c}\text { Exponential } \\
\text { Smoothing }\end{array}$ \\
\hline 2010 & 0.123 & & \\
2011 & 0.120 & & 0.123 \\
2012 & 0.133 & & 0.122 \\
2013 & 0.125 & 0.125 & 0.123 \\
2014 & 0.130 & 0.126 & 0.123 \\
2015 & 0.131 & 0.129 & 0.124 \\
2016 & 0.139 & 0.128 & 0.124 \\
2017 & 0.130 & 0.133 & 0.125 \\
2018 & 0.123 & 0.133 & 0.125 \\
2019 & 0.138 & 0.130 & 0.125 \\
2020 & & 0.130 & 0.126 \\
2021 & & 0.130 & 0.126 \\
2022 & & 0.132 & 0.126 \\
\hline
\end{tabular}


Table 4. The time series forecast from the average EVI pass Smoothing Algorithm by RMMEH method

\begin{tabular}{cccc}
\hline Year & EVI $_{\mathrm{RMM}_{-} \mathrm{t}}$ & Moving Average & $\begin{array}{c}\text { Exponential } \\
\text { Smoothing }\end{array}$ \\
\hline 2010 & 0.124 & & \\
2011 & 0.128 & & 0.124 \\
2012 & 0.133 & 0.128 & 0.124 \\
2013 & 0.131 & 0.130 & 0.125 \\
2014 & 0.130 & 0.131 & 0.125 \\
2015 & 0.134 & 0.132 & 0.125 \\
2016 & 0.139 & 0.134 & 0.126 \\
2017 & 0.131 & 0.134 & 0.126 \\
2018 & 0.130 & 0.133 & 0.126 \\
2019 & 0.138 & 0.133 & 0.127 \\
2020 & & 0.134 & 0.128 \\
2021 & & 0.135 & 0.128 \\
2022 & & & 0.128 \\
\hline
\end{tabular}

Besides, it was found that the average EVI that had smoothing algorithm by using RMMEH method of the forecasted years which were $2020-2022$ by using moving averages method were $0.133,0.134$, and 0.135 , respectively, and by using exponential smoothing method, were 0.128, 0.128, and 0.128, respectively. From the forecast of the original average EVI that the moving averages method was closer to the original average EVI than the exponential smoothing method. The results of forecast of the average EVI that had smoothing algorithm by using RMMEH method were found that the moving average was closer to the EVI that had smoothing algorithm by RMMEH method than the exponential smoothing method.

\section{Checking for accuracy of the forecast}

The results from checking for the accuracy of the forecast by both methods to see which forecasting techniques were of least errors, from 1) MAD and 2) MAPE; the less MAD and MAPE, the better the forecast. The results from checking for the accuracy of the forecast as mentioned could be shown in Table 5. Table 5 showed that errors from both methods were very little and in close proximity. It was found from the forecast that data that passed smooth algorithm by RMMEH method using moving average were best accurate and better than by using the original average EVI.

Table 5. The results from checking for the accuracy

\begin{tabular}{ccccc}
\hline \multirow{3}{*}{ Methods } & \multicolumn{2}{c}{ EVI } & \multicolumn{2}{c}{ RMMEH } \\
\cline { 2 - 5 } & $\begin{array}{c}\text { Moving } \\
\text { Average }\end{array}$ & $\begin{array}{c}\text { Exponential } \\
\text { Smoothing }\end{array}$ & $\begin{array}{c}\text { Moving } \\
\text { Average }\end{array}$ & $\begin{array}{c}\text { Exponential } \\
\text { Smoothing }\end{array}$ \\
\hline MAD & 0.00542 & 0.00722 & 0.00357 & 0.00733 \\
MAPE & $4.107 \%$ & $5.420 \%$ & $2.650 \%$ & $5.472 \%$ \\
\hline
\end{tabular}


According to results of time series change forecast of the average EVI from Terra/Modis Satellite data to examine the drought condition during 10 years (2010 - 2019) in Yasothon Province and by comparing the results between the original EVI and data that passed smoothing algorithm by RMMEH method, with the use of both methods including moving average method and exponential smoothing method, it could be concluded as follows:

(1) To classify the level of drought conditions from EVI during 10-year period, in each year it was possible to make a comparison; if EVI is lower than the means which is 0 to -1 , it means that the drought condition is highly severe; if EVI is approaching near 1, it means the vegetation is fertile thus no occurrence of drought condition or little drought condition. According to this study, it can be seen that during 10-year period, the average EVI in each year was very low, suggesting clearly that there was the occurrence of drought condition in the area. And it was found that in 2011, the drought condition was higher than that in other years in the 10 -year period since the average EVI was equal to 0.120 which was very close to 0 .

(2) From the analysis of Table 2 showing RMMEH method used in adjusting the average EVI, it was found that the average EVI adjusted by RMMEH method was higher than the original EVI, suggesting that RMMEH method could reduce the variable of primary data suitably.

(3) It was found from the comparison of the forecast by checking for accuracy of forecast using MAD and MAPE, it was found that the MAD and MAPE of the forecast of the original average EVI and the average EVI adjusted by RMMEH method were slightly different, and the average EVI adjusted by RMMEH method with the forecast by moving average was best accurate.

(4) It was found from the time-series change forecast of EVI that the original EVI and the EVI that had smoothing algorithm by RMMEH in the forecasted years during 2020 - 2022 by using moving average and exponential smoothing had very low means in each year, suggesting that the drought condition will occur in the future.

Many researchers have applied satellite data in combination with vegetation indices such as NDVI SVI and EVI to monitor drought. For example, the study titled "Performance of Smoothing Methods for Reconstructing NDVI Time-Series and Estimating Vegetation Phenology from MODIS Data" by (Cai et al., 2017), the study titled "Remote Sensing Based Drought Monitoring in the Middle-part of Northeast Region of Thailand" by (Rotjanakusol \& Laosuwan, 2018), the study titled "An Investigation of Drought around Chi Watershed during Ten-year Period using Terra/Modis Data" by (Rotjanakusol \& Laosuwan, 2019). All three researches mentioned above can be concluded that using satellite data together with vegetation indices can effectively monitor drought.

Additionally, in this study similarly found that the result was in the same direction with other research such as A Novel Compound Smoother-RMMEH to Reconstruct MODIS NDVI Time Series (Jin \& Xu, 2013), Normalized Difference Vegetation Index Times Series Change Forecasting Using. Moving 
Averages Method and Exponential Smoothing Methods (Sangpradid, 2017). Both studies concluded that when applying the data of average EVI adjusted by smoothing algorithm using RMMEH method, the results were more accurate.

\section{CONCLUSIONS}

Drought in Thailand straight affects the agriculture and water source since Thailand is the country where the people do farming particularly growing rice; moreover, Thailand is classified as one of the largest field of rice production in the world. Regularly, the drought in Yasothon Province that straight affects agriculture happens in rainy season where the rainfall is missing for an extended period of time. In this research, the focus was on forecasting time series change of the average enhanced vegetation index to monitoring drought condition by using Terra/MODIS data. From this study it can be concluded that the adjustment by smoothing the average EVI using RMMEH method can be applied with other methods also. The adjustment of the average EVI by RMMEH could help decrease the variance of data; and the map of level of drought condition created by using EVI data of Yasothon Province of Thailand during 10-year period showed clearly the drought areas. Therefore, if the plan is prepared in advanced before the situation, it will efficiently help alleviate and handle the impact from the drought.

\section{REFERENCES}

Auntarin, C., Chunpang, P., Chokkuea, W., \& Laosuwan, T. (2021): Using a Aplitwindow Algorithm for the Retrieval of the Land Surface Temperature via Landsat8 OLI/TIRS. Geographia Technica, 14 (2), 74-83. DOI: 10.21163/ GT_2019.142.07

Cai, Z., Jönsson, P., Jin, H., \& Eklundh, L. (2017): Performance of Smoothing Methods for Reconstructing NDVI Time-Series and Estimating Vegetation Phenology from MODIS Data. Remote Sensing, 9 (12), 1271. DOI:10.3390/rs9121271

Dutta, D., Kundu, A., Patel, N., Saha, S., \& Siddiqui, A. (2015): Assessment of agricultural drought in Rajasthan (India) using remote sensing derived Vegetation Condition Index (VCI) and Standardized Precipitation Index (SPI). The Egyptian Journal of Remote Sensing and Space Science, 18(1), 53-63. DOI: 10.1016/j.ejrs.2015.03.006

Fan, H., Fu, X., Zhang, Z., \& Wu, Q. (2015): Phenology-Based Vegetation Index Differencing for Mapping of Rubber Plantations Using Landsat OLI Data. Remote Sensing, 7(5), 6041-6058. DOI: 10.3390/rs70506041

Furtuna, P., Haidu, I., Alexe, M., \&Holobaca, I. (2015): Change detection in the Cluj forest district, using remote sensing and GIS application. Environmental Engineering and Management Journal, 15 (6), 1361-1367.

Gomasathit, T., Laosuwan, T., Sangpradit, S., \& Rotjanakusol, T. (2015): Assessment of Drought Risk Area in Thung Kula Rong Hai using Geographic Information Systems and Analytical Hierarchy Process. International Journal of Geoinformatics, 11(2), 21-27.

Gu, Y., Brown, J.F., Verdin, J. P. \& Wardlow, B. (2007): A five-year analysis of MODIS NDVI and NDWI for grassland drought assessment over the central Great Plains of the United States. Geophysical Research Letters, 34(6), 1-6. 
Holben, B.N., \& Justice, C.O. (1981): An Examination of Spectral Band Ratioing to Reduce the Topographic Effect on Remotely Sensed Data. International Journal of Remote Sensing, 2, 115-133.

Jin, Z., \& Xu, B. (2013): A Novel Compound Smoother-RMMEH to Reconstruct MODIS NDVI Time Series. IEEE Geoscience and Remote Sensing Letters, 10(4), 942-946. DOI: 10.1109/LGRS.2013.2253760

Kogan, F. N. (2001): Operational space technology for global Vegetation Assessment. Bull. Amer. Meteor. Soc., 82(9), 1949-1964.

Klisch, A., \& Atzberger, C. (2016): Operational Drought Monitoring in Kenya Using MODIS NDVI Time Series. Remote Sensing, 8(4), 267. DOI: 10.3390/rs8040267

Lines, D., Werner, M., \& Bastiaanssen, W. (2017): The predictability of reported drought events and impacts in the Ebro Basin using six different remote sensing data sets. Hydrol. Earth Syst. Sci., 21, 4747-4765. DOI: 10.5194/hess-21-4747-2017

Laosuwan, T., Sangpradid, S., Gomasathit, T., \& Rotjanakusol, T. (2016): Application of Remote Sensing Technology for Drought Monitoring in Mahasarakham Province, Thailand, International Journal of Geoinformatics, 12 (3), 17-25.

Li, A., Wang, Q., Bian, J., \& Lei, G. (2015): An Improved Physics-Based Model for Topographic Correction of Landsat TM Images. Remote Sensing, 7(5), 62966319. DOI: $10.3390 /$ rs 70506296

Li, L., Friedl, M., Xin, Q., Gray, J., Pan, Y., \& Frolking, S. (2014): Mapping Crop Cycles in China Using MODIS-EVI Time Series. Remote Sensing, 6(3), 24732493. DOI: $10.3390 /$ rs6032473

Matsushita, B., Yang, W., Chen, J., Onda, Y., \& Qiu, G. (2007): Sensitivity of the Enhanced Vegetation Index (EVI) and Normalized Difference Vegetation Index (NDVI) to Topographic Effects: A Case Study in High-density Cypress Forest. Sensors, 7(11), 2636-2651. DOI: 10.3390/s7112636

Mongkolsawat, C., Thirangoon, P., Suwanwerakamtorn, R., Karladee, N., Paiboonsak, S. \& Champathet, P. (2001): An evaluation of drought risk area in Northeast Thailand using remotely sensed data and GIS. Asian Journal of Geoinformatics, 1, 33-44.

Nistor, M.M., Man, T.C, Benzaghta, M.A., Nedumpallile Vasu, N., DezsiI, Ş. \& Kizza, R. (2018): Land Cover and Temperature Implications for the Seasonal Evapotranspiration in Europe. Geographia Technica, 13(1), 85-108. DOI: 10.21163/GT_2018.131.09

Peters, J.A., Walter-Shea, E.A., Ji, L., Andres, V., Michael, H. \& Svoboda, M.D. (2002): Drought Monitoring with NDVI-Based Standardized Vegetation Index. Photogrammetric Engineering\&Remote Sensing, 68(1), 71-75.

Piamdee, J., \& Laosuwan, T. (2021) Analysis into the Coastal Change due to the Critical Erosion against the Areas Around the Lower Gulf of Thailand using Satellite Data and Spatial Analysis Model. International Journal of Advanced Research in Engineering and Technology, 12(4), 2021, 469-483 DOI: 10.34218/IJARET.12.4.2021.045.

Prohmdirek, T., Chunpang, P., \& Laosuwan, T. (2020): The Relationship between Normalized Difference Vegetation Index and Canopy Temperature that Affects the Urban Heat Island Phenomenon. Geographia Technica, 15(2), 222-234. DOI: 10.21163/GT_2020.152.21 
Rotjanakusol, T., \& Laosuwan, T. (2018): Remote Sensing Based Drought Monitoring in the Middle-part of Northeast Region of Thailand. Studia Universitatis "Vasile Goldis" Seria Stiintele Vietii (Life Sciences Series), 28(1), 14-21.

Rotjanakusol, T., \& Laosuwan, T. (2019): An Investigation of Drought around Chi Watershed during Ten-year Period using Terra/Modis Data. Geographia Technica, 14 (2), 74 - 83. DOI: 10.21163/GT_2019.142.07

Rotjanakusol, T., \& Laosuwan, T. (2019): Drought Evaluation with NDVI-based Standardized Vegetation Index in Lower Northeastern Region of Thailand. Geographia Technica, 14 (1), 118 - 130. DOI: 10.21163/GT_2019.141.09

Sangpradid, S. (2017): Normalized Difference Vegetation Index Times Series Change Forecasting Using Moving Averages Method and Exponential Smoothing Methods. EAU Heritage Journal Science and Technology, 11(1), 185-195.

Seekaw, A., Mongkolsawat, C., \& Suwanwerakamtorn, R. (2014): Using standardized vegetation index to assess drought areas in Northeast Thailand. Journal of Remote Sensing and GIS Association of Thailand, 15 (2), 25-38.

Thavorntam, W., Tantemsapya, N., \& Armstrong, L. (2015): A combination of meteorological and satellite-based drought indices in a better drought assessment and forecasting in Northeast Thailand. Natural Hazards, 77(3), 1453-1474. DOI: 10.1007/s1106 9-014-1501-0

Tucker, C.J. (1979): Red and Photographic Infrared Linear Combinations for Monitoring Vegetation.Remote Sensing of Environment, 8(2), 127-150.

Uttaruk, Y. \& Laosuwan, T. (2017): Drought Detection by Application of Remote Sensing Technology and Vegetation Phenology. Journal of Ecological Engineering, 18(6), 115-121. DOI: 10.12911/22998993/76326

Uttaruk, Y., \& Laosuwan, T. (2018): Community Forest for global warming mitigation: the technique for estimation of biomass and Above Ground Carbon Storage using Remote Sensing method. Agriculture and Forestry, 64 (3), 47-57. DOI: 10.17707/AgricultForest.64.3.04

Uttaruk, Y., \&Laosuwan, T. (2020a): Methods of estımation for above ground carbon stock in Nongbua-nonmee community forest, Maha Sarakham Province, Tha1land. Agriculture and Forestry, 66 (3), 183-195. DOI: 10.17707/AgricultForest.66.3.15

Uttaruk, Y., \& Laosuwan, T. (2020b): Comparison of Carbon Storage Measurement Methods on Agroforestry Systems in Sakon Nakhon Province, Northeast Thailand. Scientific Journal of King Faisal University, 21(2), 95-99. DOI: $10.37575 / \mathrm{b} / \mathrm{sci} / 2382$

Vrieling, A., Meroni, M., Shee, A., Mude, A. G., Woodard, J., de Bie, C. A. J. M. \& Rembold, F. (2014): Historical extension of operational NDVI products for livestock insurance in Kenya. International Journal of Applied Earth Observation and Geoinformation, 28, 238-251. 